\title{
A Pharmaceutical Approach \& Antifungal Activities of Copper Soaps with their N \& S Donor Complexes Derived from Mustard and Soyabean Oils
}

\author{
PragyaTank, Rashmi Sharma and Arun Kumar Sharma* \\ Department of Chemistry, S.P.C. Govt. College, Ajmer-305001 Rajasthan, India
}

Submission: September 22, 2017; Published: October 13, 2017

*Corresponding author: Arun Kumar Sharma, Department of Chemistry, S.P.C. Govt. College Ajmer- 305001, Rajasthan, India, Email: sharmaarun423@gmail.com

\section{Abstract}

Fungicidal studies have also been done so as to understand the toxicity patterns of Copper-Mustard soap, Copper-Soyabean soap and their complexes on Alternaria alternata fungi at varying concentrations using agar plate technique. The effect of solvent has been excluded by complete evaporation. Fungicidal activity is measured in terms of \% inhibition. The \% Inhibition is calculated according to the following equation: $-\%$ Inhibition $=(\mathrm{C}-\mathrm{T}) / \mathrm{C} * 100$

Where $\mathrm{C}$ and $\mathrm{T}$ are the diameter of fungal colony in control plate and test plate respectively after 72 hours. In general, it has also been concluded that CMU complexes are more active than CSU complexes. All the physico-chemical and fungicidal analysis reported by us will play a significant role in their application in industries and various other fields.

\section{Introduction}

Copper fungicides rapidly developed after the 'accidental' discovery of the Bordeaux mixture. The Bordeaux mixture [1]. (Copper sulphate and hydrated lime) was the first fungicide to be used on a large scale world- wide [2,3]. Recent studies conducted showed that the use of copper significantly reduced the numbers of bacteria, filamentous fungi and yeast on leaf and fruit surfaces [4]. Recently the deeper understanding of the role of metal ion in biosystem has led to the awareness that metal complexion is useful in the treatment of bacterial, fungicidal and viral diseases.

The pathogenic activity of organic antimicrobial agents is enhanced on complexation with various transition and toxic metals. The biological effect of these derivatives depends on the nature and structure of ligands and their metal complexes and also on the presence of the particular element [5-8]. Many copper compounds are employed as pesticides either alone [as $\mathrm{Cu}$ (II) oxide and $\mathrm{Cu}$ (II) sulphate] or in mixture like Bordeaux mixture and Burgundy mixture-fungicide similar to Bordeaux mixture but containing sodium carbonate instead of lime. Nitrogenous ligands have been found to be effective against many metal enzymes, bacteria and number of fungi. Large number of compounds containing nitrogen and sulphur atoms in the heterocyclic ring shows different types of activities [9-12].
Recently, Wood has developed antagonist theory of drug action and Fields led to the synthesis of several co-ordination compounds, which have been used for antibacterial and anti-tubercular activity [13-14]. Some newly synthesized 2-arylamino-4-fluoroarylthiazoles, which were evaluated for biological activities, were found to possess fungicidal, herbicidal and anti-arthritic activities [15-17]. Various workers [18-19] synthesized and evaluated the biological activity of copper complexes with tridentate ligands and studied the $\mathrm{N}$-heterocyclic ligands and assessed their remarkable insecticidal activity. A number of heterocyclic derivatives proved to be very useful insecticides and were used in crop protection [20-21].

It has also been established that chelation of the nitrogen and sulphur containing compounds and their substituted derivatives enhances the biological and fungicidal activity [22-26]. The use of copper linoleate as heavy-duty wood preservative and other biological activities of surfactants containing copper metal have also been studied [27]. Small quantities of copper soaps such as copper stearate, copper oleate and copper abietate (from resins) are employed mainly for rot proofing textiles, rope etc. The main applications of Copper sulfate are in the field of wood preservatives and agricultural fungicides. 
copper napthenate is a widely used, broad spectrum wood preservatives .It has several properties related to effective control of decay fungi and excellent control or mitigation of wood destroying insects, including termites, beetles, carpenter ants and other host organisms which makes it a highly valued commodity. In United States, The Environmental Protection Agency also classifies copper napthenate as a general use (unrestricted) pesticide.

All the above studies suggest that copper metal as well as nitrogen and sulphur containing compounds play a vital role in fungicidal activities. Various edible oils are widely used, easily available, and are eco- friendly. These facts led us to synthesize copper soaps of edible oils and their complexes with ligands containing nitrogen and sulphur elements, to study their micellar characteristics and investigate the role of copper metal in fungicidal activities for exploring their applications and possible uses in various industries and agriculture. For this purpose, we have chosen to study the fungicidal activity of the synthesized copper soaps and complexes against easily available fungi Alternaria alternata.

\section{Experimental}

\section{Anti-fungal testing}

The general laboratory techniques followed in the course of this investigation are as suggested by literature [28].

\section{Sterilization of glass wares}

Glassware's used in our present study were of Pyrex brand. The glassware viz. test tubes, conical flasks, pipette (micro and macro), glass rods and Petri-dishes were thoroughly washed after rinsing with chromic acid each time before sampling. The Petri plates and other glassware's were then sterilized in hot air oven at $160{ }^{\circ} \mathrm{C}$ for 24 hours before use.

\section{Culture media used}

The culture medium used for the growth of the organism of the present study was P.D.A. The following media were used in the present study.

$\begin{array}{lll}\text { Potatoes } & - & 200 \mathrm{~g} \\ \text { Dextrose } & - & 20 \mathrm{~g}\end{array}$

Agar $\quad 20 \mathrm{~g}$

Distilled water $\quad$ - $\quad 1000 \mathrm{ml}$

$200 \mathrm{~g}$ of potatoes were cleaned, cut into pieces and boiled in about $1000 \mathrm{ml}$ of tap water for 2 hours. Then, the contents were strained using muslin cloth. To this extract $20 \mathrm{~g}$ of dextrose, $20 \mathrm{~g}$ of agar were added and made up to $1000 \mathrm{ml}$ in graduated flask, before sterilizing the medium.

\section{Preparation of sample solutions}

All the copper soaps and complexes derived from Mustard and Soyabean oil have been tested for their antifungal activity. The method of preparation of soap and complexes has been described in [29]. All the chemicals used were of LR/AR grade. The calculated amount of soap / complex was weighed in a standard flask and the solutions containing different concentrations (100, 1000 and $10000 \mathrm{ppm}$ ) of soap / complex in benzene were prepared.

\section{Test organism}

The test organism used in the present study was Alternaria alternata; which was isolated from its natural habitat [plants, debris] and then purified characterized and identified.

\section{Fungicidal testing}

I ml of sample solution was aseptically transferred into sterile Petri plates. Into these plates, $20 \mathrm{ml}$ of P.D.A. was poured and was mixed with sample solution by rotating the Petri plates in clock wise and anti-clock wise direction 3-4 times, and was allowed to solidify. After the solidification of the above medium, single hypha/spore of test organism were aseptically transferred in the centre of the Petri plates. The plates were incubated at $30 \pm 10^{\circ} \mathrm{C}$ for 72 hours. After the period of incubation, the plates were observed for the growth of fungus in different concentration of the soap/complex solution used in the present study. The data were statistically analyzed according to the following formula

$$
\% \text { Inhibition } \quad=\quad(\mathrm{C}-\mathrm{T}) / \mathrm{C} * 100
$$

Where $\quad \mathrm{C}=$ diameter of fungal colony in control plate after 72 hours

$\mathrm{T}=$ diameter of fungal colony in test plate after 72 hours

\section{Results and Discussion}

Table 1: \% inhibition for copper soaps and complexes derived from mustard oil.

\begin{tabular}{|c|c|c|c|c|c|c|}
\hline \multirow{2}{*}{$\begin{array}{l}\text { Soap Complex/ } \\
\text { Concentration }\end{array}$} & \multicolumn{2}{|c|}{ 100ppm } & \multicolumn{2}{|c|}{ 1000ppm } & \multicolumn{2}{|c|}{ 10000ppm } \\
\hline & $2 \mathrm{ml}$ & $5 \mathrm{ml}$ & $2 \mathrm{ml}$ & $5 \mathrm{ml}$ & $2 \mathrm{ml}$ & $5 \mathrm{ml}$ \\
\hline $\mathrm{CM}$ & 76.6 & 83.3 & 85 & 89 & 58.3 & 44.4 \\
\hline CMU & 78.8 & 82.2 & 91.6 & 94 & 61 & 52.7 \\
\hline CMB & 83.3 & 88.8 & 88 & 97.7 & 66.6 & 72.2 \\
\hline
\end{tabular}


Global Journal of Pharmacy \& Pharmaceutical Sciences

Table 2: \% Inhibition for copper Soaps and Complexes Derived from Soyabean Oil.

\begin{tabular}{|c|c|c|c|c|c|c|}
\hline \multirow{2}{*}{$\begin{array}{l}\text { Soap Complex/ } \\
\text { Concentration }\end{array}$} & \multicolumn{2}{|c|}{ 100ppm } & \multicolumn{2}{|c|}{ 1000ppm } & \multicolumn{2}{|c|}{ 10000ppm } \\
\hline & $2 \mathrm{ml}$ & $5 \mathrm{ml}$ & $2 \mathrm{ml}$ & $5 \mathrm{ml}$ & $2 \mathrm{ml}$ & $5 \mathrm{ml}$ \\
\hline $\mathrm{CM}$ & 66.6 & 71.1 & 76.6 & 85.5 & 22.2 & 38.8 \\
\hline $\mathrm{CMU}$ & 78.8 & 81.1 & 92.7 & 96.6 & 42.2 & 55.5 \\
\hline CMT & 76.6 & 80 & 83.3 & 94.4 & 28.8 & 11.11 \\
\hline $\mathrm{CMB}$ & 75.5 & 77.7 & 77.7 & 86.6 & 16.66 & 33.33 \\
\hline
\end{tabular}

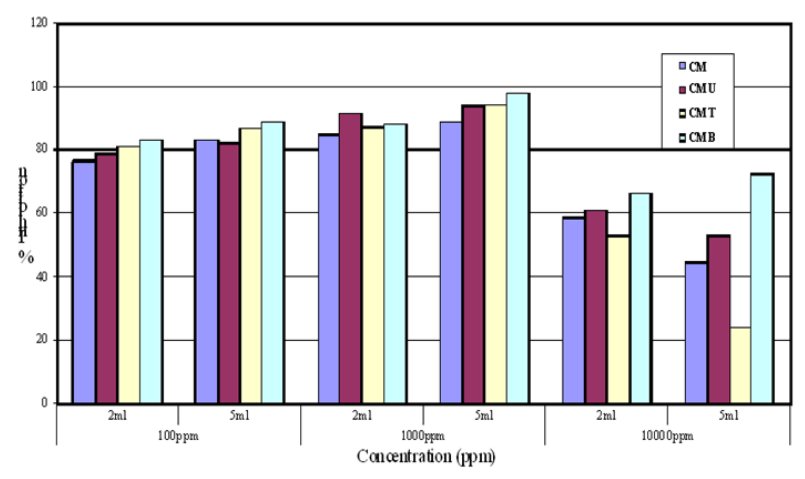

Figure 1: \% Inhibition for copper Soaps and complexes Derived from Mustard seed oil.

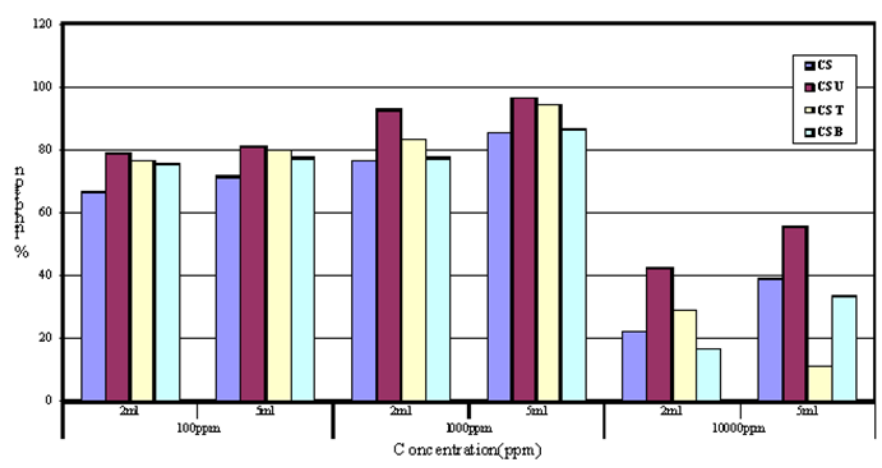

Figure 2: \% Inhibition for copper Soaps and complexes Derived from Soyabean oil.

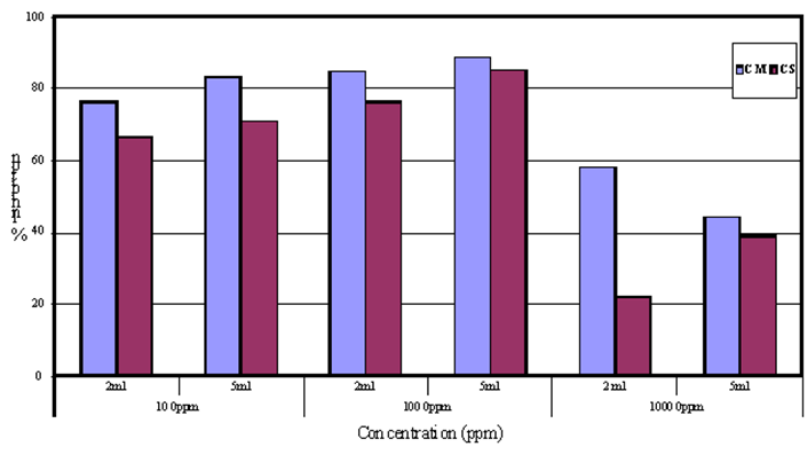

Figure 3: \% Inhibition for copper Soaps Derived from Mustard and Soyabean oil. 


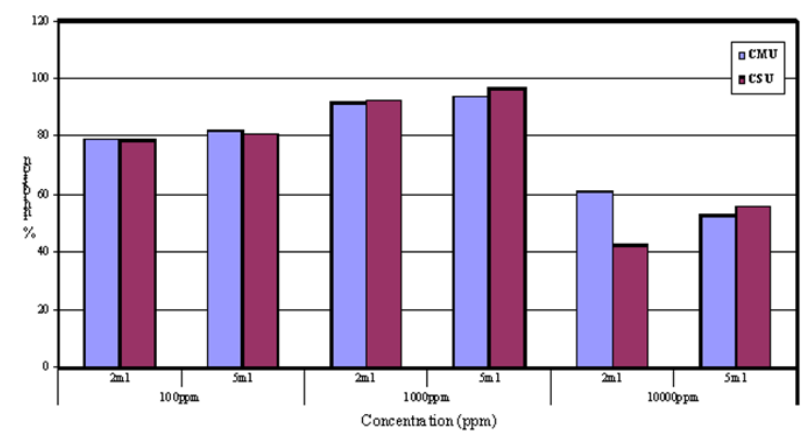

Figure 4: \% Inhibition for Urea complexes of copper soaps Derived from Mustard and Soyabean oil.

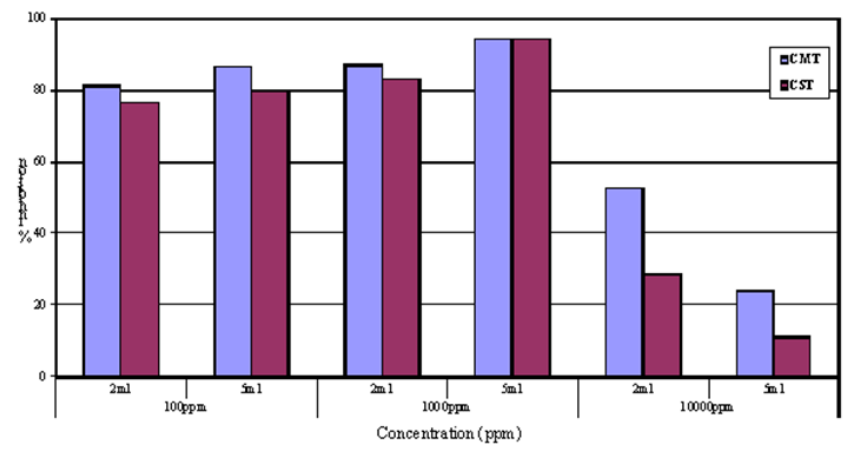

Figure 5: \% Inhibition for Thiourea complexes of copper soaps Derived from Mustard and Soyabean oil.

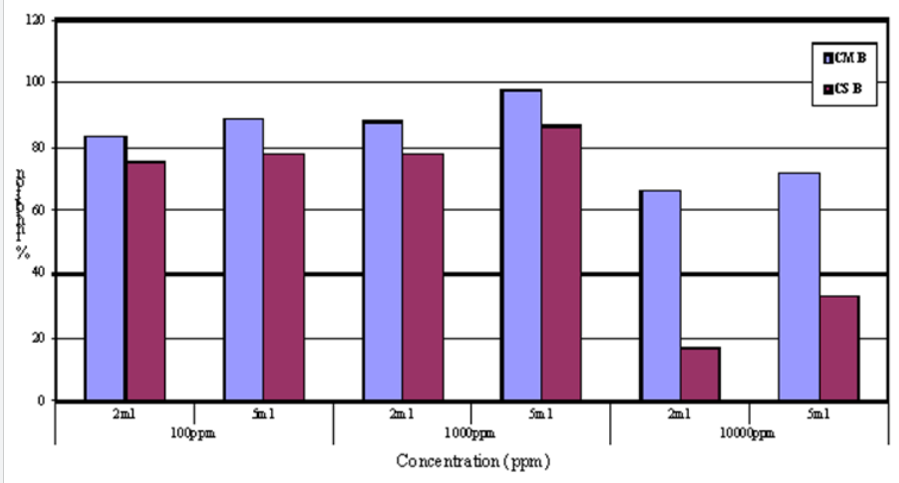

Figure 6: \% Inhibition for Benzothiazole of copper soaps Derived from Mustard and Soyabean oil.

The anti-fungal activities of copper soaps and their corresponding complexes with ligands like Urea, Thiourea and substituted Benzothiazole have been screened against Alternaria alternata at $100 \mathrm{ppm}, 1000 \mathrm{ppm}$ and $10000 \mathrm{ppm}$ using $2 \mathrm{ml}$ and $5 \mathrm{ml}$ of these solutions by agar-plate technique [29]. A perusal of (Table 1\&2) reveals that all complexes show higher activity than pure soaps (Figure 1\&2) suggesting that complexes are more powerful antifungal agents; and Benzothiazole and other N,S etc. containing compounds are able to enhance the performance of copper soaps.
The enhanced activity of newly synthesized complexes as compared to those of the soaps could possibly be explained on the basis of presence of donor atoms $\mathrm{N}$ and $\mathrm{S}$ atom as well as the structural compatibility with molecular nature of the toxic moiety. A perusal of (Table 1\& 2) Shows a very interesting pattern of $\%$ inhibition with increasing concentration. For all the soaps and complexes, on increasing the concentration from $100 \mathrm{ppm}$ to $1000 \mathrm{ppm}$, the $\%$ inhibition increases but on increasing the concentration from $1000 \mathrm{ppm}$ to $10000 \mathrm{ppm}$, there has been unexpected decrease in \% inhibition for all systems. The comparative order could be summarized as: 
\% Inhibition: $100 \mathrm{ppm}<1000 \mathrm{ppm}>10000 \mathrm{ppm}$

This could possibly be explained on the basis of their CMC. It has been calculated that the concentration of $100 \mathrm{ppm}$ and 1000 ppm lie below CMC for all soaps and complexes, whereas the concentration of $10000 \mathrm{ppm}$ lies above CMC. This observation suggests that the molecule shows an effective activity against the fungal growth and individually plays an important role in the inhibition of fungal growth, whereas when the concentration of the solute increases in the solution (i.e. concentration is higher than $\mathrm{CMC}$ ) the molecule aggregates to form micelle and their behavior and activity against the fungal growth has been affected significantly.

Thus the possibility cannot be denied that after the formation of micelles, the biocidal behavior shows deviation and the concentration taken is an important factor. Also, on increasing the amount of solution in Petri plates from $2 \mathrm{ml}$ to $5 \mathrm{ml}$, the \% inhibition increases, suggesting that the \% inhibition is affected by the increase in the concentration of the active fungicidal moiety in the analyzed system. On the basis of earlier works, where fungicidal analyses of pure ligand (Benzothiazole), soap and their complexes were conducted; it was observed that enhanced activity of complexes was due to synergistic mechanism, i.e. free ligand and pure soap show less activity but on complexation show enhanced activity. These results support our studies where pure soaps and ligands show less inhibition whereas on complexation show enhanced activity.

A perusal of (Table 1) shows that CM soap is the least fungi toxic (\% inhibition lowest) whereas its Benzothiazole complex CMB shows highest inhibition. The activity of copper soap and complexes derived from Mustard oil (Figure 1) are found to increase in the order:

\section{$\mathrm{CMB}>\mathrm{CMT}>\mathrm{CMU}>\mathrm{CM}$}

This may be attributed to the fact that the atom introduced into the complex through the ligand also plays an important role in enhancing the effectiveness of fungicidal molecule. The result shows that the fungicidal activity increases as the nitrogen and oxygen atoms are introduced in the complex through Urea ligand; it further shows another increase due to sulphur atom introduced through Thiourea ligand.

The CMB molecule shows maximum fungicidal effect due to presence of two nitrogen atoms, one sulphur atom, one benzene ring and one chlorine atom introduced through Benzothiazole ligand in the complex. These results clearly indicate that atom present in the molecule, concentration, structure, CMC etc. and other factors are very important and play significant role in enhancing the activity of fungicide. On studying (Table 2), it is revealed that CS is the least toxic and has lowest \% inhibition, whereas Urea complex shows highest \% inhibition in all concentration ranges (Figure 2).

$$
\mathrm{CSU}>\mathrm{CST}>\mathrm{CSB}>\mathrm{CS}
$$

It has also been observed that, in general, copper soaps and complexes derived from Mustard oil show higher \% inhibition as compared to those derived from Soyabean oil i.e. CM > CS. These results are depicted graphically in (Figure 3-6). All the studies done by us will provide valuable information regarding their selection in various industries.

\section{Conclusion}

The general trend so observed for all the three concentrations i.e. $10^{2} \mathrm{ppm}, 10^{3} \mathrm{ppm}$ and $10^{4} \mathrm{ppm}$ indicate that fungicidal activity of complexes is higher than that observed for soaps. These results also suggest that \% inhibition increases with the complexation of soaps, as nitrogen and sulphur atoms are included in the soap molecule after complexation. Further, for all the soaps and complexes studied, it is observed that the \% inhibition increases on increasing the amount of solution in the Petri-plate from $2 \mathrm{ml}$ to $5 \mathrm{ml}$.

It has also been observed that the activity increases with the increase in the concentration of solution from $102 \mathrm{ppm}$ to $103 \mathrm{ppm}$. But as the concentration is further raised from $103 \mathrm{ppm}$ to $104 \mathrm{ppm}$, the activity decreases in all the cases. This observation may be interpreted as, in general, activity is more pronounced at lower concentrations $\left(10^{2} \mathrm{ppm}\right.$ and $\left.10^{3} \mathrm{ppm}\right)$ but at high concentration $\left(10^{4} \mathrm{ppm}\right)$, the surfactant becomes less active due to its micellar behavior i.e. when the concentration is taken more than $\mathrm{CMC}$, the molecule aggregates in the solution phase and after the evaporation of the solvent they act differently as compared to the dilute solutions. This observation clearly suggests that for better results the dilute solutions should be taken and the concentration should be below CMC.

\section{Acknowledgment}

The authors pay their sincere gratitude to CSIR, New Delhi for Finance and Principal, S. D. Govt. College, Beawar- 305901 Rajasthan (India) and S.P.C. Government College Ajmer for providing necessary research facilities to accomplish this study.

\section{References}

1. Tank P, Sharma A.K. and Sharma R. (2017) Thermal Behaviour and Kinetics of Copper (II) Soaps and Complexes Derived from Mustard and Soyabean Oil. J Anal Pharm Res 4(2):00102. DOI: 10.15406/ japlr.2017.04.00102.

2. Fugui MB, Ndahi NP, Paul BB, Mustapha AN (2013) Synthesis, characterization, and antimicrobial studies of some vanillin Schiff base metal (II) complexes. J Chem Pharm Res 5(4): 22-28.

3. Rai BK, Vidyarthi SN, Sinha P, Singh V, Kumar S (2013) Spectroscopic and biocidal study of Co (II), Cu (II) and Ni (II) chelates of nitrogen and sulphur containing Schiff base derived from 6-methyl-2-phenyl4H-chromen-one. Orient J Chem 29(1): 271-276.

4. Khan S. Sharma R. Sharma A. K. (2017) Antifungal Activities of Copper Surfactants derived from Neem (Azadirecta Indica) and Karanj (Pongamiapinnata) Oils: A Pharmaceutical Application Glob J Pharmaceu Sci 3(4): 1-6.

5. Shiekh RA, Rahman IA, Malik MA, Luddin N, Masudi SM, et al. (2013) 
Transition metal complexes with mixed nitrogen-sulphur (N-S) donor macro cyclic Schiff base ligand: synthesis, spectral, electrochemical and antimicrobial studies. Int. J. Electro chem Sci 8: 6972 -6987.

6. Choudhary A, Sharma R, Nagar M (2011) Synthesis, characterization and antimicrobial activity of mixed ligand complexes of Co (II) and $\mathrm{Cu}$ (II) with N, O/S donor ligands and amino acids. Int Res J Pharm Pharmacol 1(6): 172-187.

7. Sharma S., Sharma R. Sharma A.K. (2017) Synthesis, Characterization, and thermal degradation of $\mathrm{Cu}$ (II) Surfactants for sustanable green chem. Asian Journal of Green Chemistry, 2(2), 129-140 DOI:10.22631/ ajgc.2017.95559.1015.

8. Yadav PS, Devprakash, Senthilkumar GP (2011) Benzothiazole different methods of synthesis and diverse biological activities. International Journal of Pharmaceutical Sciences and Drug Research 3(1): 1-7.

9. Sharma R, Saxena M, Sharma N (2012) Synthesis, spectroscopic and fungicidal studies of copper soaps derived from mustard and soyabean oils and their urea complexes. Int J Chem Sci 10(1): 143-149.

10. Angelusiu MV, Almajan GL, Ilies DC, Rosu T, Negoiu M (2008) Cu(II) complexes with nitrogen-oxygen donor ligands: synthesis and biological activity. Chem Bull 53(67):1-2.

11. Raman N, Joseph J, Velan AS, Pothiraj C (2006) Antifungal activities of biorelevant complexes of copper (II) with biosensitive macrocyclic ligands. Mycobiology 34(4): 214-218.

12. Borhade SS (2012) Synthesis, characterization and antimicrobial activity of copper (II) with 2-chloroquinoline-3-carbaldehyde thiosemicarbazide $\quad\{1-((2-$ chloroquinolin-3-yl $)$ methylene $)$ thiosemicarbazide (2-chloro- QAT). Int J Pharm \& Life Sci 3(1): 1344 1350 .

13. Tihile MS, Murade PA (2013) Complexes of 4, 6-dinitrobenzothiazole2 -amine acetate with some transition metal ions. Journal of Chemical and Pharmaceutical Research 5(2): 5-9.

14. Tank Pand Sharma R. , Sharma A.K. (2017) Studies of Ultrasonic and acoustic parameters of complexes derived from Copper (II) surfactant of mustard oil with $\mathrm{N}$ and $\mathrm{S}$ atoms containing ligands in non aquous media (benzene) at $303.15 \mathrm{~K}$ J Acous Soc Ind :44,(2) (in press).

15. Prakasha R, Sharma N, Chaturvedi K (2012) Spectroscopic and antimicrobial studies of mixed ligand complexes of transition metal (II) ions with nitro quinoline and dibenzoylmethan. Sci Revs Chem Commun 2(2): 108-114.

16. National Committee for Clinical Laboratory Standards (2004) Reference method for antifungal disc diffusion susceptibility testing yeasts proposes guideline M44-A, NCCLS, Wayne, PA, USA.

17. National Committee for Clinical Laboratory Standards (2002) Reference method for antifungal disc diffusion susceptibility testing yeasts propose guideline M27-A2, NCCLS, Wayne, PA, USA.

18. Bipasa S, Abhijit R (2013) Synthesis, Characterization, Biocidal activity and Phytototoxic effect of Mn (II) Fe (II) Co (II) $\mathrm{Cu}$ (II) $\mathrm{Zn}$ (II) complexes of 3,5-dinitro benzoic acid. International Journal of Analytical Pharmaceutical and Biomedical Sciences (2): 1-7.

19. Sharma S. Sharma R. heda L.C. and Sharma A.K. (2017) Kinetic parameters and Photo Degradation studies of Copper Soap derived from Soyabean Oil using $\mathrm{ZnO}$ as a Photo catalyst in Solid and Solution Phase.J. Inst. Chemists (India), 89 (4), (in press).

20. Chandra S, Ballabh P (2013) Synthesis, characterization and physicochemical studies of $\mathrm{Ni}$ (II) and $\mathrm{Cu}$ (II)complexes with some nitrogen- oxygen and nitrogen sulphur donor ligands. Int J Pharm Sci Res 1-4(6): 2393-2399.

21. Joseph J, Boomadevi JG (2014) Synthesis, structural characterization and biological studies of copper complexes with 2-amino benzothiazole derivatives. Journal of Material and Environment Science 5(3): 693704.

22. Olagboye SA, Hassan GF (2013) Synthesis, Characterization and Biocidal Evaluation of Azole based Ligands metal Complexes. International Journal of Applied Science and Biotechnology 1(4): 258265.

23. Mathur N, Heda LC, Mathur VK, Saxena P (2011) Study of CLSI-M44-A Disk Diffusion method for determining the susceptibility of candida species against novel complexes derived from copper stearate with 2-amino benzothiazoles. Tenside Surfactant Detergents 48(1): 23-27.

24. Sharma A.K. Saxena M. Sharma R. (2017) Ultrasonic studies of Cu (II) Soaps derived from Groundnut and Sesame oils Tens. Surf. Det. (in press).

25. Sharma R, Saxena M, Acharya S (2012) Volumetric and viscometric studies of copper (II) surfactant derived from four edible oils in methanol-benzene mixture. Journal of Indian Chemical Society 89(5): 585-592.

26. Sharma A.K. Saxena M. Sharma R. (2017) Ultrasonic studies of Cu (II) Soaps derived from Groundnut and Sesame oils Tens. Surf. Det. (in press).

27. Chandra S, Ballabh P (2013) Synthesis, Characterization and Physicochemical Studies of Ni (II) and Cu (II) Complexes with some nitrogen- oxygen and nitrogen sulphur donor ligands. International Journal of Pharmaceutical Science and Research 4(6): 2393-2399.

28. Bauer AW, Perry DM, Kirby WM (1959) Single disc antibiotic sensitivity testing of Staphylococci. Archive of Internal Medicine 104(2): 208-216.

29. Bauer AW, Kirby WM, Sherris JC, Turck M (1966) Antibiotic susceptibility testing by a standardized single disk method. American Journal of Clinical Pathology 45(4): 493-496.

\section{Your next submission with Juniper Publishers will reach you the below assets}

- Quality Editorial service

- Swift Peer Review

- Reprints availability

- E-prints Service

- Manuscript Podcast for convenient understanding

- Global attainment for your research

- Manuscript accessibility in different formats (Pdf, E-pub, Full Text, Audio)

- Unceasing customer service

Track the below URL for one-step submission https://juniperpublishers.com/online-submission.php 